\title{
XLV. On an improvement in the apparatus for procuring potassium
}

\section{William Mandell B.D.}

To cite this article: William Mandell B.D. (1822) XLV. On an improvement in the apparatus for procuring potassium , Philosophical Magazine Series 1, 60:294, 247-249, DOI: 10.1080/14786442208652832

To link to this article: http://dx.doi.org/10.1080/14786442208652832

曲 Published online: 29 Jul 2009.

Submit your article to this journal $₫$

Q View related articles $₫$ 
of most effectually obviating such malpractices in future. I take this opportunity to express my entire concurrence with the two clauses in the Act for altering of the present weights and measures, which require that tables of equalization and conversion from the quantities and values of present measures to that of the imperial measure, shall be prepared and published.

I was so thoroughly convinced of the necessity of this, that I actually prepared tables of equalization and conversion, as to quantity and value, from all the multifarious measures in the British empire to that of the imperial standard. And as the Act is put off until next Session, I mean then to be also prepared with similar tables to convert from all foreign standards to the same standard; thoroughly convinced that, if I am any way seconded in my efforts, I shall be enabled to give to the world one of the greatest advantages, in a commercial point of view, which has ever been submitted to the public. And as I doubt not that truth and equity are the prominent characteristics of your publication, and that you will readily admit the necessity of accuracy, in a great commercial nation like ours, in matters involving the best interests of thousands of its inhabitants, I am persuaded that you will permit me to endeavour, in your next, to obviate the evils of which I complain.

I have the honour to be, gentlemen,

Your most obedient humble servant,

Wm. Gutteridge.

XLV. On an Improvement in the Apparatus for procuring Potassium. By William Mandeli, B.D. Fellow of Queen's College.*

$\mathbf{O}_{\mathbf{N}}$ repeating the late Professor Tennant's experiment for procuring potassium + , (which differs from the similar one first made by the French chemists, Gay-Lussac and Thenardf, principally in being more simple and commodious for practice,) it occurred to me, that one part of the apparatus made use of, might, with advantage, be still further simplified: and as every circumstance, however apparently obvious or trivial in itself, which, in any degree, tends to facilitate the production, in greater quantity, of so powerful a chemical agent as potassium, is of importance, I have thought that the mode of

* From the Cambridge Philosophical Transactions for 1892, Part II.

+ Philosophical Transactions for 1814, p. 578, to which the reader is referred for the detail of the process. See Phil. Mag. vol. xliii. 457.

$\ddagger$ Annales de Chimic, tom. lxvi. p. 205 .

operating 
operating which I pursued might not be wholly unworthy the notice of this Society.

It is well known that the grand difficulty in successfully performing the experiment in question, consists in protecting the gun-barrel from the effects of that extreme and long-continued heat, which is necessary to decompound the alkali, and to volatilize its base. The usual practice hitherto has been to surround with a lute*, that portion of the gun-barrel which is introduced into the fire. This operation, however, is always tedious; and although it be conducted even with the greatest care, it is found extremely difficult to prevent fissures in the coating, particularly when the heat is much increased in the course of the experiment. Hence, if eventually the fire have direct access to the barrel, through any crevice which may be formed, the fusion of the denuded part is generally the consequence, and the whole labour of the experiment is lost.

This, then, being the common cause of failure, it occurred to me that, if there were substituted for the luting, a thin but sound and well-burnt tube or hollow cylinder of Stourbridge clay, of such dimensions as just to cover that portion of the barrel which is subjected to the fire, the unfortunate result, which I have alluded to, might possibly be avoided.

A tube of this description was accordingly procured; and, in order to guard against the hazard of its cracking, by reason of exposure to a sudden increase of temperature, it was, in the first place, gradually and with caution, heated to redness.

The remaining part of the experiment was then performed with entire success; and a very considerable quantity of potassium obtained.

It may be proper to remark that the hollow cylinder, and that portion of the gun-barrel which it incloses, should be of such relative diameters that, when cool, their corresponding surfaces are not quite in close contact; otherwise, the cylinder will be in danger of bursting, not only on account of its own contraction, but also on account of the simultaneous expansion of the gun-barrel, from the effects of that very high temperature, to which, in this state of combination, they are submitted.

Moreover, the whole apparatus should be supported accurately in the same position, throughout the experiment, (by means of rests made of Stourbridge clay, and should be so

* "On couvre cette partie moyenne d'un lut infusible."-Gay-Lussac et Thenard, Ann. de Chim. tom. lxvi. p. 207 .

"The lute which I have found most effectual ...... was composed ...... of Stourbridge clay ......\&c."-Tennant, Phil. Trans. for 1814 , p. 582.

"It (the gun-barrel) is then covered with an infusible lute."-Brande's Manual of Chemistry, p. 184. Ed. 1819. 
situate in the fire, that the materials operated upon may during the whole process be subjected to its greatest intensity.

With due attention to these precautions, and to some minor circumstances in the manipulation of the experiment, which I shall not take up the Society's time in detailing, it is believed that the decomposition of potash, by means of iron, might in every instance be effected with almost entire certainty, and potassium be obtained in great abundance.

\section{On the Origin and Disconery of Iron. By} DaYid Mushet, Esq.*

[Continued from pagre $16 \%$.]

However rude an instrument, in the hands of the early ironmaker, we may in our times consider the blast-bloomery to have been, yet there can be no doubt that in an operation so different from, and so much more complete than, the more ancient air-bloomery, many difficulties attended its general introduction. Prior to this, bellows must have been invented and in common use, and their construction substantial and well understood, before they were made powerful enongh to smelt ores of iron. It is also very probable that they were long used to forge the iron produced in the air-bloomery, before they were applied to the department of smelting.

Accident alone in almost every instance is the source or cause of invention. Anomalies in the arts and manufactures appear and vanish without notice or attention; and it is only when these fall under the observation of persons of investigating habits, that they are ever philosophically accounted for, or made subservient to useful or beneficial purposes. Bellows, in the first instance, were likely applied in the bloomery upon any occasional diminution of the usual or necessary current of air; by and by some advantage as to quality, produce, or time, might be procured, which would give rise to their more general introduction towards the concluding part of the process, in order more $\mathrm{c} \cdot \mathrm{mpletely}$ to separate the iron from its oxide and from the earths, and to unite the masses more firmly together, to withstand the shock of the hammer. The partial application of the bellows, however, was widely different from its more general application to the purposes of smelting. In the old process the pieces of ore were matured by a long period of cementation; but no perfect fusion or separation took place. The metallic particles coalesced, and part of the oxides and earths were discharged in consequence of their being fusible

* Communicated by the Author:

Vol. 60. No. 294. Oct. 1822. 